\title{
The epidemiology of hospitalized influenza in children, a two year population-based study in the People's Republic of China
}

\author{
Wei $\mathrm{Ji}^{1 \dagger}$, Tao Zhang ${ }^{2 \dagger}$, Xuelan Zhang ${ }^{1}$, Lufang Jiang ${ }^{2}$, Yunfang Ding ${ }^{1}$, Chuangli Hao ${ }^{1}$, Liwen Ju², Yuqing Wang ${ }^{1}$,
} Qingwu Jiang ${ }^{2}$, Mark Steinhoff', Steven Black ${ }^{3}$, Genming Zhao ${ }^{2^{*}}$

\begin{abstract}
Background: The epidemiology and disease burden of annual influenza in children in mainland People's Republic of China have not been reported in detail. To understand the incidence and epidemiology of laboratory-proven influenza hospitalization in children in China, a review of available laboratory and hospital admission data was undertaken.

Methods: We conducted a retrospective population-based study in Suzhou and the surrounding area of Jiangsu province, China for hospitalized cases of respiratory illness at Suzhou Children's Hospital. Cases of pneumonia or respiratory illness were identified from hospital computer data bases. Routine virological testing by fluorescent monoclonal antibody assay of all hospitalized children identified influenza and other viruses. We calculated incidence rates using census population denominators.
\end{abstract}

Results: Of 7,789 specimens obtained during 2007 and 2008, 85 were positive for influenza A and 25 for influenza B. There were 282 specimens with parainfluenza virus and 1392 with RSV. Influenza occurred throughout the year, with peaks in the winter, and in August/September. Overall estimated annual incidence of laboratory-proven influenza hospitalization was 23-27/100,000 children 0-4 years old, and 60/100,000 in infants 0-6 months, with an average hospitalization of 9 days.

Conclusions: Influenza disease in young children in this part of China is a relatively common cause of hospitalization, and occurs throughout the year. The use of influenza vaccine in Chinese children has the potential to reduce the effect of influenza in the children, as well as in their communities. Studies are needed to further assess the burden of influenza, and to develop and refine effective strategies of immunization of young children in China.

\section{Background}

Influenza is an important cause of morbidity and mortality among both children and adults. Influenza A and $B$ viruses cause yearly epidemics with significant morbidity and mortality globally [1]. Children have the highest rates of infection while elderly adults have the highest mortality rates [2]. Influenza is also associated with substantial numbers of hospitalizations among young infants and children [3]. Neuzil et al., reported

\footnotetext{
* Correspondence: gmzhao@shmu.edu.cn

† Contributed equally

${ }^{2}$ Department of Epidemiology, School of Public Health, Fudan University, Key Laboratory of Public Health Safety, Ministry of Education, Shanghai, PR China
}

during periods when influenza virus was circulating, the rate of excess hospitalizations for cardiopulmonary conditions ranged from 104 to 9 per 10,000 children/year for children 0-59 months. Healthy infants were hospitalized for illness attributable to influenza at rates similar to those for high-risk adults [4]. A recent prospective population surveillance study in three US states confirmed these earlier findings with average annual rates of hospitalization attributable to influenza of 450 per 100,000 children/year for children less than 6 months of age (reaching annual hospitalization rates of $1 \%$ in some years). Rates $/ 100,000$ children annually ranged from 30 to 90 for those between 6-59 months of age with an

\section{Biomed Central}

(ㄷ) $2010 \mathrm{Ji}$ et al; licensee BioMed Central Ltd. This is an Open Access article distributed under the terms of the Creative Commons Attribution License (http://creativecommons.org/licenses/by/2.0), which permits unrestricted use, distribution, and reproduction in any medium, provided the original work is properly cited. 
overall incidence of 90 . In addition, outpatient visits associated with influenza were 10 to 250 times more common than hospitalizations in younger US children [5].

For many years influenza vaccination was recommended only for children with high-risk medical conditions in the US. However, because of the high rates of hospitalization in healthy US children this recommendation was expanded in 2004-2005 to include all children 6-23 months of age and again in 2006-2007 to include all children 6-59 months of age, regardless of medical condition [6,7]. In 2008-2009, the recommendation was extended even further to include all children, aged 6 months to 18 years [8].

Several studies have shown that young children are important in the spread of community influenza since they often introduce the infection to their families, and disseminate infection through schools to the broader community [9]. In addition there is substantial evidence from the US, Italy, and Japan that immunization of young children can reduce disease rates in unimmunized members of the local community $[10,11]$.

Most influenza strains that cause epidemic and pandemic disease appear to arise out of Asia, with East Asia being a common source [12]. Despite the importance of this region as a source of new many influenza strains, the epidemiology and burden of disease of influenza, especially in the 87 million 0-5 year old children of China has not been described. Importantly, influenza vaccination is not routinely recommended in China and immunization of children is uncommon.

In order to further the understanding of the burden and epidemiology of influenza in children in China, a review of available laboratory and hospital admission data was undertaken at the Suzhou university affiliated Children's Hospital in Jiangsu province in China. This hospital was chosen because it is the only children's hospital serving Suzhou district, which has a population of approximately 6 million people and an annual birth cohort of approximately 40,000 infants. Suzhou is located near Shanghai, approximately 31 degrees North and 120 degrees West, at a latitude similar to Jacksonville Fl in N America or Cairo, Egypt. See figure 1 for a summary of meteorological data, which is typical for a humid sub tropical latitude.

The hospital has computerized diagnostic records for all admissions, facilitating identification and characterization of all respiratory admissions and importantly has been performing virologic testing on all children admitted to the respiratory wards and ICU for the past two years.

\section{Methods}

This was a retrospective sentinel hospital surveillance study using available clinical, laboratory and demographic data. Cases hospitalized for pneumonia were identified from computerized hospital medical records for the years 2007-2008. The Criteria for diagnosing pneumonia was a clinical diagnosis of pneumonia by the treating physician as recorded in chart. Age specific population denominators for Suzhou and the surrounding area served by the hospital were estimated from the population census for Jiangsu province for the years 2007 to 2008 . Hospitalization rates were then calculated for each year for which computerized hospital data was available. For the past two years it has been the policy of the hospital to perform virologic testing routinely on all children admitted with a respiratory complaint. All children hospitalized with acute respiratory disease are admitted to one of two dedicated respiratory wards which have dedicated staff to perform this and other routine procedures. In addition, children admitted to the PICU also have routine respiratory virologic testing.

Virologic testing is performed on nasal aspirate specimens which are forwarded to the microbiology laboratory where an immuno-fluorescent kit ( $D^{3}$ Ultra DFA Respiratory Virus Screening and Identification kit, Diagnostic Hybrids, of Athens, Ohio USA) was used according to the manufacturer's directions. This assay allows identification of adenovirus, influenza A, influenza B, parainfluenza 1,2 , and 3 , and RSV viruses from clinical specimens using fluorescein-tagged monoclonal antibodies and utilizes positive and negative controls. In addition, nucleic acid from each positive specimen is banked for possible future testing.

The case count for pneumonia hospitalization was used to assess the annual epidemiology of respiratory infection in this population. In addition, the influenza data was used along with the population denominators described above to estimate the age specific rates of hospitalization for influenza in this population for the study years. These calculations assume that few local children would have been hospitalized outside of Suzhou, Jiangsu province, as this is the only children's hospital in the area.

The study was approved by the Institute Review Board in the School of Public Health at Fudan University which is registered with the office for human research protections and has a federal wide assurance (approval no. IRB \#09-03-0171).

\section{Results}

From Jan 2007 through Dec 2008, there were 7,789 specimens sent for virus screening (3,444 in 2007 and 4,345 in 2008, 63\% male). All the specimens came from 0-59 month old children admitted to Suzhou Children's Hospital for respiratory infection. In total there were 95 specimens positive for influenza $A$ and 25 for influenza B with an overall positivity rate of $1.54 \%$, ranging up to 10 


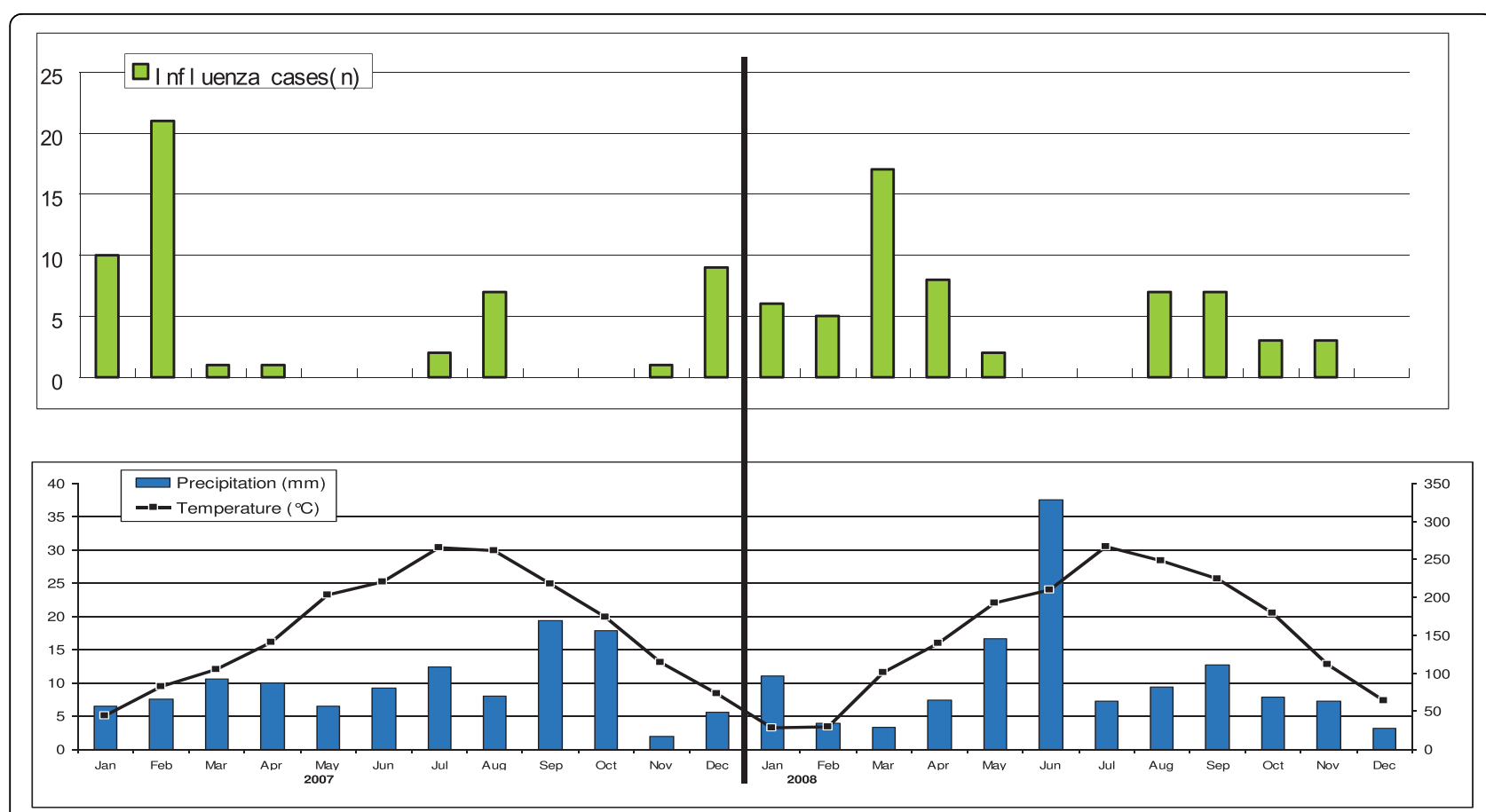

Figure 1 Monthly distribution of number of influenza cases, precipitation, and mean temperature in Suzhou, China. Mean relative humidity ranged from $60-75 \%$ over this period, and is not displayed.

per cent in peak months. In addition, there were 282 positives for parainfluenza (types 1, 2 and 3 being 30, 2 and 250 cases respectively) and 1392 (17.87\%) with RSV and 60 with adenovirus infection. It is likely that some patients $0-28$ days old who were admitted to the newborn unit rather than the respiratory wards did not have routine specimens submitted for virology.

The seasonal distribution of the influenza cases is shown in Figure 1. Influenza cases occurred year round, for $18 / 24$ months, most commonly in the winter and early spring (January - March) with a second late summer peak in August-September. The temperature and precipitation for the same time period in Suzhou is also shown in Figure 1. Not shown is the humidity during the same time period which was constant varying between $60-75 \%$. The seasonal distribution of cases for both years combined is shown in Figure 2. The two peaks of disease in the winter and late summer can be more clearly seen in this figure. Hospitalization for influenza was most common in 0-6 month old infants as is shown in Figure 3 and Table 1. Figure 4 shows the monthly distribution of influenza types from nearby Shanghai for 2008, showing the distribution of influenza viruses subtypes in the winter and summer peaks which differed for this year. As shown in Table 2, the most common discharge diagnosis for hospitalized patients with proven influenza was bronchopneumonia, with pneumonia in a patient with asthma being second.
Lengths of stay for children with influenza tended to be relatively long ranging between 7 and 14 days with the average being 9.42 days and 10.02 days in 2007 and 2008 respectively. Nine (8.2\%) children with influenza required ICU care. All children with a confirmed diagnosis of influenza received at least one antibiotic, with beta-lactams and macrolides being the most common, respectively.

Although influenza virus sub-typing was not available for Suzhou viruses during the study period, data from Shanghai, which is 100 kilometers distant, revealed that the most common influenza subtype during the winter of 2008 was $A / H 3 N 2$, during which time influenza B also circulated. In the summer of $2008, \mathrm{~A} / \mathrm{H} 1 \mathrm{~N} 1$ predominated with no influenza B, as is shown in Figure 4.

We noted that the seasonality of influenza contrasted with the seasonality of RSV and parainfluenza. RSV occurred only in the fall and winter, whereas parainfluenza was most common in the summer months.

\section{Discussion}

China reports 17 million births per year, about 13\% of the world's birth cohort. We are not aware of a previous publication estimating the population incidence and patterns of laboratory-proven influenza in children in mainland China. A previous study estimated the rates of influenza indirectly from seasonal data of hospitalization in Hong Kong [13]. 


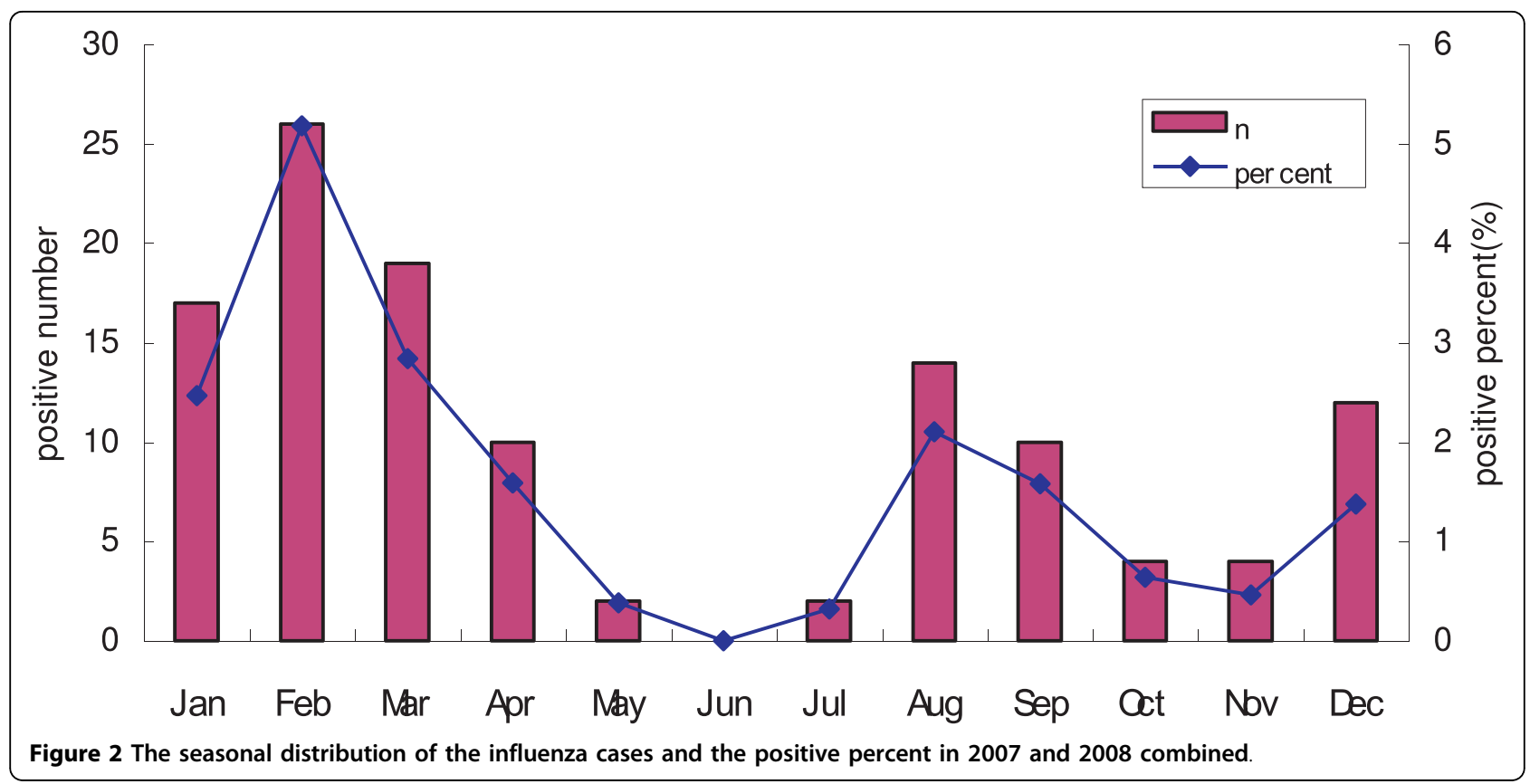

Our study data demonstrate that respiratory illness and specifically pneumonia is the most common cause of hospitalization for children under five in Suzhou, China. Overall, $2-3 \%$ of all children less than 5 years were hospitalized with a diagnosis of pneumonia. Despite the relatively high level of economic growth and development in this region, hospitalization rates are high, although mortality is very low. This would seem to indicate that the threshold for admission for respiratory illness is relatively low, as described by Chiu in Hong Kong [13]. In a planned prospective study we will evaluate the severity of illness of hospitalized children and assess the incidence of outpatient disease. Prior to the availability of this information, anecdotal information from pediatricians at the hospital would seem to confirm our impression that the one child policy in China encourages parents to seek care for their children when they are only mildly ill. However, a substantial portion of children admitted also required ICU care indicating that the case mix may be complex. Introduction of childhood influenza vaccination has the potential to reduce a substantial proportion of these influenza-associated hospitalizations.

It is of interest that influenza associated hospitalization of children occurs during 8-9 months of the year, in a perennial pattern, with two distinct annual peaks. This pattern is also reported from nearby Hangzhou, Zhejiang province [14]. This contrasts with the classical

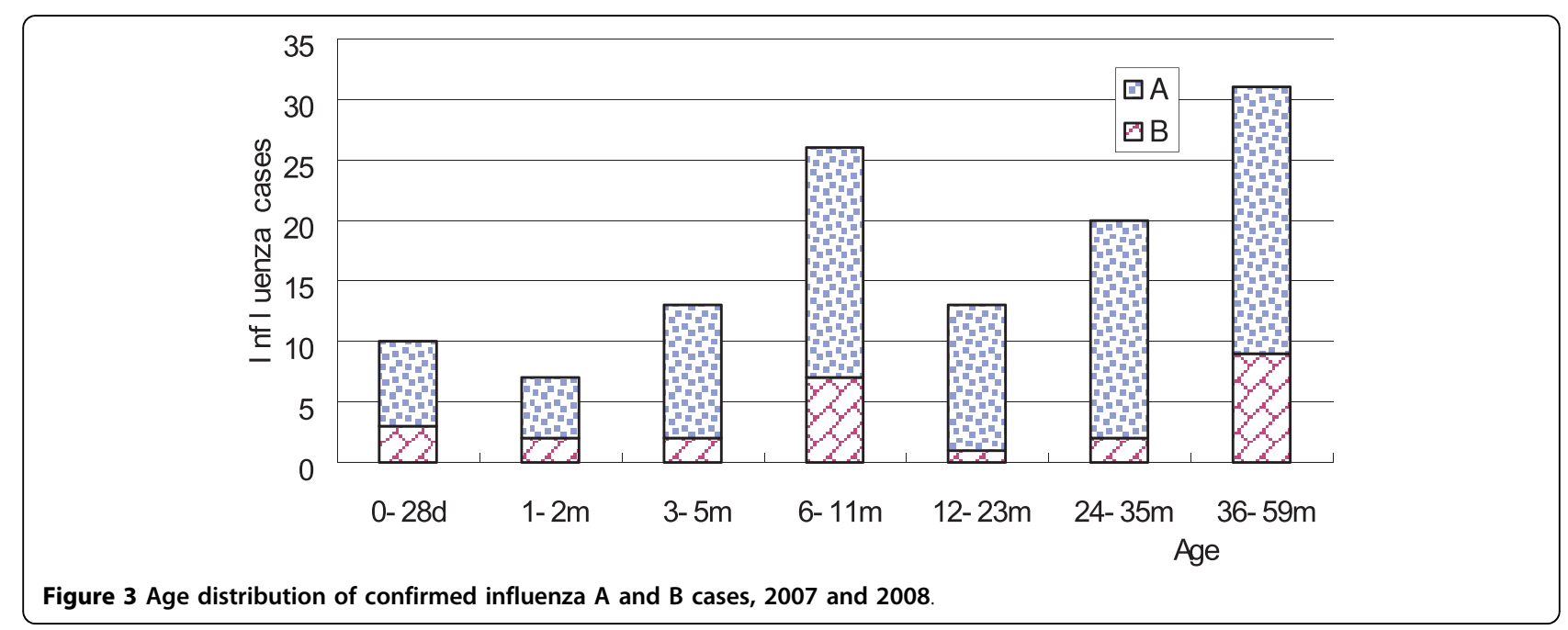


Table 1 Estimated age-specific annual incidence/100,000 population of all-cause pneumonia and of lab-proven influenza hospitalization

\begin{tabular}{|c|c|c|c|c|c|c|c|}
\hline \multirow[t]{2}{*}{ Year } & \multirow[t]{2}{*}{ Age } & \multirow{2}{*}{$\begin{array}{l}\text { Est. } \\
\text { Pop. }\end{array}$} & \multirow[t]{2}{*}{ Total Hospitalized Children } & \multicolumn{2}{|c|}{ Hospitalized Pneumonia } & \multicolumn{2}{|c|}{ Influenza - Related Hospitalization } \\
\hline & & & & No. (death) & Incidence(95\%Cl) & Number & Incidence $(95 \% \mathrm{Cl})$ \\
\hline \multirow[t]{5}{*}{2007} & $0-5 \mathrm{~m}$ & 24,261 & 3,311 & $2,147(3)$ & $8,850(8492-9207)$ & 15 & $61.8(30.5-93.1)$ \\
\hline & 6-11 m & 24,261 & 2,986 & 1,529 & 6,302 (5997-6608) & 14 & $57.7(27.5-87.9)$ \\
\hline & $12-23 \mathrm{~m}$ & 48,522 & 2,302 & $910(2)$ & 1,875 (1755-1996) & 3 & $6.2(0.8-13.2)$ \\
\hline & 24-35 m & 48,522 & 4,556 & $884(2)$ & 1,822 (1703-1941) & 8 & $16.5(5.1-27.9)$ \\
\hline & $36-59 m$ & 97,044 & 5,014 & 1,311 & $1,351(1278-1424)$ & 15 & $15.5(7.6-23.3)$ \\
\hline Total & $0-59 m$ & 242,610 & 18,169 & $6,781(7)$ & $2,795(2729-2861)$ & 55 & $22.7(16.7-28.7)$ \\
\hline \multirow[t]{5}{*}{2008} & $0-5 \mathrm{~m}$ & 23,886 & 3,367 & $2,395(4)$ & $10,027(9646-10408)$ & 15 & $62.8(31.0-94.6)$ \\
\hline & 6-11 m & 23,886 & 2,979 & $1,700(1)$ & 7,117 (6791-7443) & 12 & $50.2(21.8-78.7)$ \\
\hline & $12-23 m$ & 47,772 & 2,744 & 1,011 & $2,116(1987-2245)$ & 10 & $20.9(8.0-20.9)$ \\
\hline & 24-35 m & 47,772 & 5,433 & 982 & 2,056 (1928-2183) & 12 & $25.1(10.9-39.3)$ \\
\hline & $36-59 m$ & 95,544 & 5,985 & $1,458(2)$ & $1,526(1448-1604)$ & 16 & $16.7(8.5-25.0)$ \\
\hline Total & $0-59 m$ & 238,860 & 20,508 & $7,546(7)$ & $3,159(3089-3229)$ & 65 & $27.2(20.6-33.8)$ \\
\hline
\end{tabular}

Note: Populations estimated from the birth cohorts of 48,552 births in 2007 and 47,772 births in 2008 in Suzhou.

pattern of a single winter peak of influenza observed in Northern Europe and North America, and also with the year round circulation of influenza observed in tropical settings $[15,16]$. It is possible that this pattern may represent temporally overlapping epidemics of northern winter strains, alternating with summer strains from tropical regions and Hong Kong, as recently described by Russell et al [12]. The local virus subtype data is not available currently to evaluate this hypothesis, but the data from Shanghai shows the circulating subtypes are different each season.

The peak incidence of pneumonia hospitalization was in 0-5 month old children as reported elsewhere and in US studies. However, the annual incidence of confirmed influenza hospitalization in our study of 50-60 cases per 100,000 children $<1$ year old children is substantially lower than the rates published from the US [17]. The
Suzhou incidence we have calculated is substantially less than the incidence rates reported from Hong Kong. It is noted that the childhood influenza incidence data from Hong Kong derived from a seasonal analysis of excess hospitalization [18] has recently been modified by surveillance data based on influenza virus detection [13] to a fraction of former estimate.

The overall annual incidence of laboratory-proven influenza hospitalization we observed was 23-27/100,000 in 0-4 year old children. The average 10 day duration of hospitalization for influenza suggests a relatively large economic burden of childhood influenza in this region.

These rates of laboratory-proven influenza are a minimal estimate. The immunofluorescent assays we used are likely to underestimate the true number of virus infections, and a nucleic acid amplification test may provide more accurate data. The testing of patients from

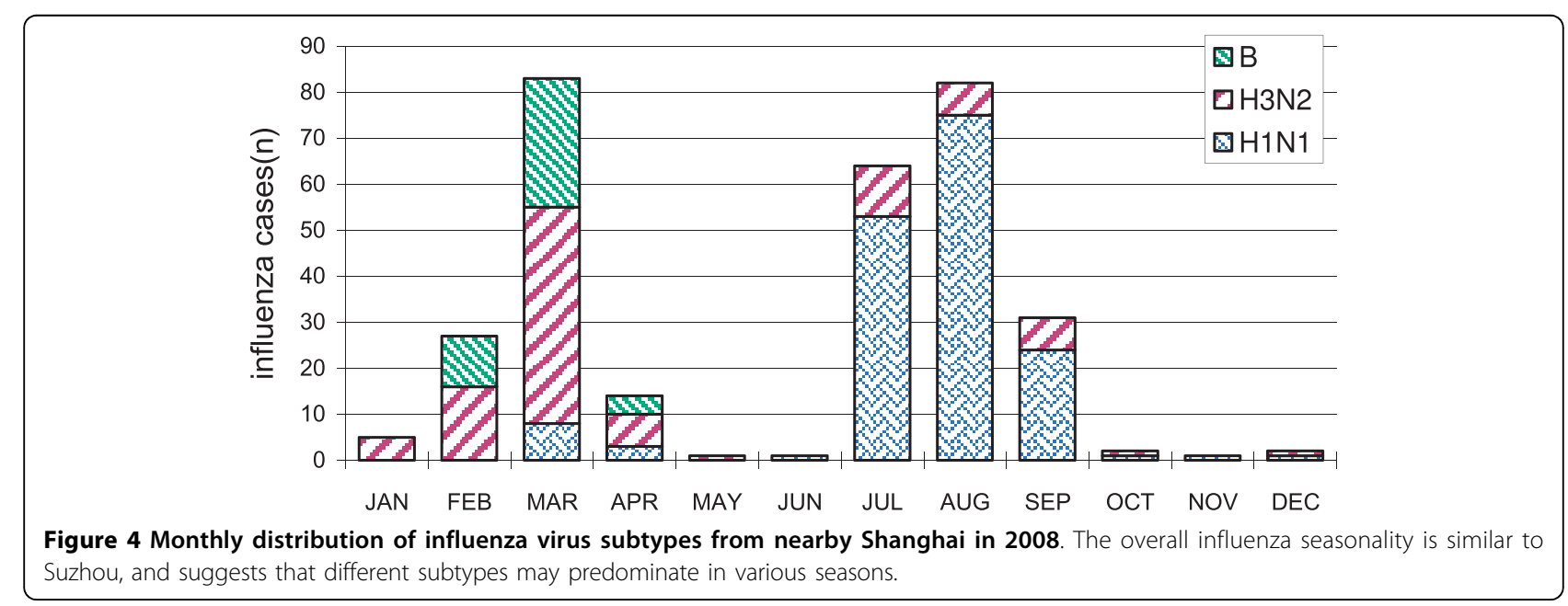


Table 2 The clinical diagnoses and selected case characteristics for the patients with confirmed influenza.

\begin{tabular}{|c|c|c|c|c|c|c|c|c|}
\hline \multirow[t]{2}{*}{ Age } & \multirow[t]{2}{*}{$N$} & \multicolumn{5}{|c|}{ Clinical Diagnosis } & \multirow{2}{*}{$\begin{array}{c}\text { Mean Hospitalization } \\
\text { Duration (days) }\end{array}$} & \multirow[t]{2}{*}{ Referral ICU } \\
\hline & & Pneumonia & $\begin{array}{l}\text { Broncho- } \\
\text { Pneumonia }\end{array}$ & $\begin{array}{l}\text { Asthma with } \\
\text { Pneumonia }\end{array}$ & Pharyngitis & Other & & \\
\hline $0-28 d$ & 10 & 10 & & & & & 7.5 & 0 \\
\hline $1-2 \mathrm{~m}$ & 7 & 1 & 4 & 1 & & $1^{A_{-}}$ & 10.6 & 2 \\
\hline $3-5 m$ & 13 & & 8 & 5 & & & 11.2 & 1 \\
\hline 6-11 m & 26 & 3 & 16 & 5 & & $2^{B}$ & 9.4 & 0 \\
\hline $12-23 m$ & 13 & 1 & 12 & & & & 9.8 & - \\
\hline $24-35 m$ & 20 & & 12 & 5 & 1 & $2^{c}$ & 9.0 & 0 \\
\hline $36-59 m$ & 31 & 2 & 20 & 3 & 3 & $3^{\mathrm{D}}$ & 9.1 & 1 \\
\hline Total & 120 & 17 & 72 & 19 & 4 & 8 & 9.46 & 4 \\
\hline
\end{tabular}

Notes: ${ }^{\text {A: }}$ Broncho-pneumonia + meningitis

B: Bronchitis

C: URI

D: URI, meningitis, bronchitis for each

the respiratory wards and ICU likely missed children with influenza who were admitted to other wards with febrile syndromes.

These data show that $25 \%$ of all admitted lab-proven cases of influenza were 0-5 months old; a group whose illness can be prevented by maternal immunization [15]. Conversely, $75 \%$ were $6-59$ months old, in the age group which receives influenza vaccine in the USA.

\section{Conclusion}

Influenza disease in young children in this part of China is a relatively common cause of hospitalization, and occurs throughout the year. Since young children play a major role in the introduction and the dissemination of new influenza viruses in communities, the use of influenza vaccine in children in China has the potential to reduce the effect of influenza in the children, as well as in their communities. Studies are needed to develop and refine effective strategies of influenza immunization of young children in China.

\section{Acknowledgements}

This research was funded by Shanghai Leading Academic Discipline Project Number: B118 and Project Number: 08-GWZX0201. We thank Prof. Tan Jianguo for his assistance in the meteorology data collection.

\footnotetext{
Author details

'Suzhou Children's Hospital, Suzhou University, Jiangsu Province, PR China. ${ }^{2}$ Department of Epidemiology, School of Public Health, Fudan University, Key Laboratory of Public Health Safety, Ministry of Education, Shanghai, PR China. ${ }^{3}$ Center for Global Health, Cincinnati Children's Hospital, Cincinnati, Ohio, USA.
}

\section{Authors' contributions}

WJ participated in the design and implement of the study. TZ performed the statistical analysis and drafted the manuscript. XZ carried out the immunoassays. $\sqcup$ participated in the implement of the study. YD participated in the design and implement of the study. $\mathrm{CH}$ participated in the design and implement of the study. $L J$ participated in its design and coordination. YW implemented the field study. QJ participated in the design and coordination. MS conceived the study, participated in the design of the study and helped to draft the manuscript. SB participated in its design, and coordination and drafted the manuscript. GZ conceived the idea,

coordination and participated in the design. All authors read and approved the final manuscript.

\section{Competing interests}

The authors declare that they have no competing interests.

Received: 8 September 2009 Accepted: 30 March 2010 Published: 30 March 2010

\section{References}

1. Thompson WW, Shay DK, Weintraub E, Brammer L, Cox N, Anderson LJ, Fududa K: Mortality associated with influenza and respiratory syncytial virus in the United States. JAMA 2003, 289(2):179-86.

2. Barker WH: Excess pneumonia and influenza associated hospitalization during influenza epidemics in the United States, 1970-78. Am J Public Health 1986, 76(7):761-5.

3. Glezen WP, Paredes A, Taber LH: Influenza in children. Relationship to other respiratory agents. JAMA 1980, 243(13):1345-9.

4. Neuzil KM, Mellen BG, Wright PF, Mitchel EF Jr, Griffin MR: The effect of influenza on hospitalizations, outpatient visits, and courses of antibiotics in children. $N$ Engl J Med 2000, 342(4):225-31.

5. Poehling KA, Edwards KM, Weinberg GA, Szilagyi P, Staat MA, Iwane MK, Bridges CB, Grijalva CG, Zhu Y, Bernstein DI, Herrera G, Erdman D, Hall CB, Seither R, Griffin MR, for the New Vaccine Surveillance Network: The underrecognized burden of influenza in young children. $N$ Engl J Med 2006, 355(1):31-40

6. Fiore AE, Shay DK, Haber P, Iskander JK, Uyeki TM, Mootrey G, Bresee JS, Cox NJ: Prevention and control of influenza. Recommendations of the Advisory Committee on Immunization Practices (ACIP), 2007. MMWR Recomm Rep 2007, 56(RR-6):1-54.

7. Smith NM, Bresee JS, Shay DK, Uyeki TM, Cox NJ, Strikas RA: Prevention and Control of Influenza: recommendations of the Advisory Committee on Immunization Practices (ACIP). MMWR Recomm Rep 2006, 55(RR10):1-42.

8. Prevention of influenza: recommendations for influenza immunization of children, 2008-2009. Pediatrics 2008, 122(5):1135-41.

9. Hurwitz ES, Haber M, Chang A, Shop T, Teo S, Ginsberg M, Waecker N, Cox NJ: Effectiveness of influenza vaccination of day care children in reducing influenza-related morbidity among household contacts. JAMA 2000, 284(13):1677-82.

10. Reichert TA: The Japanese program of vaccination of schoolchildren against influenza: implications for control of the disease. Semin Pediatr Infect Dis 2002, 13(2):104-11. 
11. Jordan R, Connock M, Albon E, Fry-Smith A, Olowokure B, Hawker J, Burls A: Universal vaccination of children against influenza: are there indirect benefits to the community? A systematic review of the evidence. Vaccine 2006, 24(8):1047-62.

12. Russell CA, Jones TC, Barr IG, Cox NJ, Garten RJ, Gregory V, Gust ID, Hampson AW, Hay AJ, Hurt AC, de Jong JC, Kelso A, Klimov Al, Kageyama T, Komadina N, Lapedes AS, Lin YP, Mosterin A, Obuchi M, Odagiri T, Osterhaus ADME, Rimmelzwaan GF, Shaw MW, Skepner E, Stohr K, Tashiro M, Fouchier RAM, Smith DJ: The global circulation of seasonal influenza A (H3N2) viruses. Science 2008, 320(5874):340-6.

13. Chiu SS, Chan KH, Chen H, Young BW, Lim W, Wong WH, Lau YL, Peiris JS: Virologically confirmed population-based burden of hospitalization caused by influenza A and B among children in Hong Kong. Clin Infect Dis 2009, 49(7):1016-21.

14. Tang LF, Wang TL, Tang HF, Chen ZM: Viral pathogens of acute lower respiratory tract infection in China. Indian Pediatr 2008, 45(12):971-5.

15. Zaman K, Roy E, Arifeen SE, Rahman M, Raqib R, Wilson E, Omer SB, Shahid NS, Breiman RF, Steinhoff MC: Effectiveness of maternal influenza immunization in mothers and infants. N Engl J Med 2008, 359(15):1555-64.

16. Viboud C, Alonso WJ, Simonsen L: Influenza in tropical regions. PLOS Med 2006, 3(4):e89.

17. Izurieta HS, Thompson WW, Kramarz P, Shay DK, Davis RL, DeStefano F, Black S, Shinefield H, Fukuda K: Influenza and the rates of hospitalization for respiratory disease among infants and young children. N Engl J Med 2000, 342(4):232-9.

18. Chiu SS, Lau YL, Chan KH, Wong WH, Peiris JS: Influenza-related hospitalizations among children in Hong Kong. N Engl J Med 2002, 347:2097-103.

\section{Pre-publication history}

The pre-publication history for this paper can be accessed here:http://www. biomedcentral.com/1472-6963/10/82/prepub

doi:10.1186/1472-6963-10-82

Cite this article as: Ji et al:: The epidemiology of hospitalized influenza in children, a two year population-based study in the People's Republic of China. BMC Health Services Research 2010 10:82.

\section{Submit your next manuscript to BioMed Central and take full advantage of:}

- Convenient online submission

- Thorough peer review

- No space constraints or color figure charges

- Immediate publication on acceptance

- Inclusion in PubMed, CAS, Scopus and Google Scholar

- Research which is freely available for redistribution

Submit your manuscript at www.biomedcentral.com/submit 